\title{
Simulation and Analysis of a Three-phase Shunt Active Power Filter
}

\author{
Asad Saleem, Jawad Zia, Muhammad Talha Ahmad, * Saad Ullah Khan, \\ Shahid Hussain Abbassi \\ Department of Electrical and Computer Engineering, Air University, Islamabad, Pakistan. \\ * Corresponding Author Email: saadullah@mail.au.edu.pk
}

\begin{abstract}
This paper presents the simulation-based study and results of a three-phase shunt active power filter (SAPF) for power quality improvement. The power quality of the power systems is degraded because of the presence of non-linear loads at the consumer end. The SAPF can reduce the impact of harmonics caused by the non-linear loads. The analyzed SAPF system is modeled and simulated using MATLAB-Simulink workspace. The ultimate goal of this study is to improve the total harmonic distortion of the system as per the standards defined by IEEE-519.
\end{abstract}

Keywords- Power Quality Improvement, Reactive Power Compensation, Shunt Active Power Filter (SAPF), Total Harmonic Distortion (THD) Reduction.

Date Received 20-11-2020

Date Accepted 01-12-2020

Date Published 18-12-2020

\section{INTRODUCTION}

In the electrical power industry, we are significantly concerned with power quality as it helps us conclude how efficiently the electric power is utilized by the load. Poor power quality causes power loss, harmonic generation due to non-linearities, and a reduction in the efficiency and life span of the electric equipment used in the power systems. In this era, for efficient power control, power electronic devices are used that are non-linear in behavior and generate harmonics in the power system. Harmonics affects the power system in various ways such as excessive heating of capacitors that are used for power factor improvement, overheating of transformer and motors, and problems in generating units while synchronizing [1], [2].

Before the advancements in the shunt active power filter (SAPF), passive filters (or LC-filters) were generally used to deal with the problems related to power quality. Some other drawbacks of passive filters are: bulkiness, provides only fixed compensation, can only be designed and operated for a certain fundamental frequency. But because of the non-dynamic nature of passive filters, scientists and engineers made their effort in developing more suitable solutions and they come up with SAPF using advanced control techniques. Some types of equipment other than active and passive filters used for power quality improvement are Line reactors, isolation and phase-shifting transformer, etc. [3].

The base of the SAPF is a PWM controlled voltage source inverter (VSI) that is connected in parallel with the load, hence called 'Shunt Active Power Filter'. The primary elements of the SAPF are VSI, a DC-Link Capacitor, and the implemented control circuitry. The efficiency of SAPF depends mainly upon the technique used for reference current generation and the control methodology used to insert the required compensation current back into the system.

The possible approaches that can be used by SAPF are based either on time-domain techniques such as Hysteresis current control technique, PI-control, sliding mode control or the frequency domain methods that include fast fourier transform (FFT), discrete fourier transform (DFT), and recursive discrete fourier transform (RDFT). However, frequency domain based methods demand huge memory, much more computation power, and the results for transient condition lack precision. On the other side, the time-domain techniques are easy to implement and understand, require less calculation, and are widely adopted for generating the reference current. Among them, hysteresis control is mostly used by SAPF [4], [5].

\section{SHUNT ACTIVE POWER FILTER (SAPF)}

SAPF is adaptable to any change in the sinusoidal waveform by comparing the load current and source voltages with the reference current waveform, and then with the help of a power converter, it generates the 'anti-harmonics'. By using SAPF; reactive power can also be compensated. SAPF is preferred over passive filter because of its dynamic response as we don't have to redesign the whole filter according to change in load conditions.

\section{A. Working of Shunt Active Power}

The principle of the SAPF is that it detects the harmonics in the power system and then produces anti-harmonics, which are equal to the harmonics in the magnitude present in the power line but $180^{\circ}$ opposite in phase. SAPF is connected in parallel to the non-linear load and helps in attaining only sinusoidal current (fundamental component) at the receiving end. In figure 1, SAPF is introduced in a circuit where $i_{L}$ is the load current, $i_{S}$ is 
the source current, and $\mathrm{i}_{\mathrm{F}}$ is the compensation current (or filter current at the output of the power converter) [6].

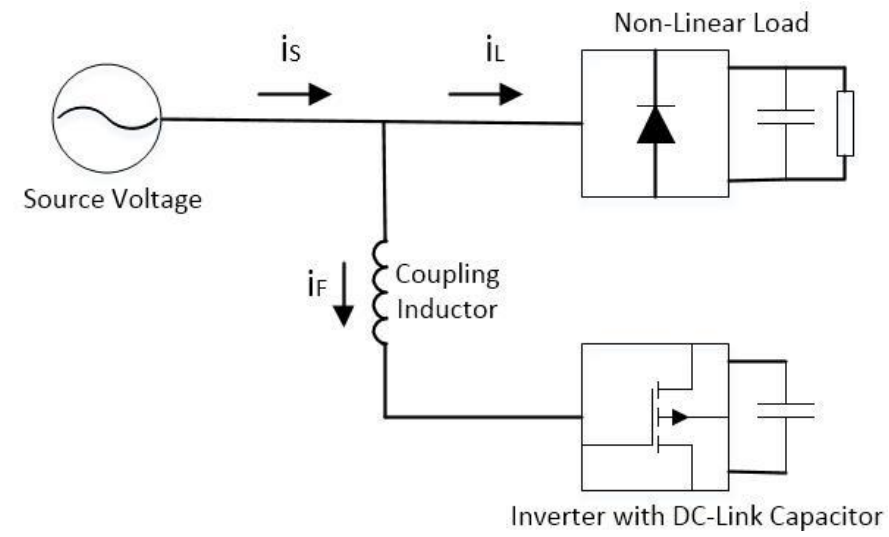

Fig. 1. Single Line Diagram of Shunt Active Power Filter

Voltages $v_{S}$ and $V_{D C}$ represent the measured source voltage and the voltage at the DC-side of the SAPF respectively. Using $\mathrm{v}_{\mathrm{S}}, \mathrm{V}_{\mathrm{DC}}$, and $\mathrm{i}_{\mathrm{L}}$, the SAPF controller continuously generates the reference current $\mathrm{I}_{\mathrm{ref}}$ in real-time.

SAPF can be subjected to two major parts:

1) Power Circuit

2) Control Circuit

SAPF keeps the track of load current and also keeps on generating the compensation current in real-time with the help of control techniques such as $\mathrm{p}-\mathrm{q}$ theory, $\mathrm{d}-\mathrm{q}$ trans-formation, Sliding mode control method, unity power factor method, Algorithms based on DSP, etc. Among these, we will be utilizing p$\mathrm{q}$ theory along with Clarke Transformation and hysteresis band current controller [7], [8],

\section{B. DC-Link Capacitor}

The DC-link capacitor has the following applications:

1) It maintains a nearly constant DC-voltage with a very small ripple at the dc side of the VSI.

2) During the transient period, it serves as an energy storage element to supply the real power demand of load from the source.

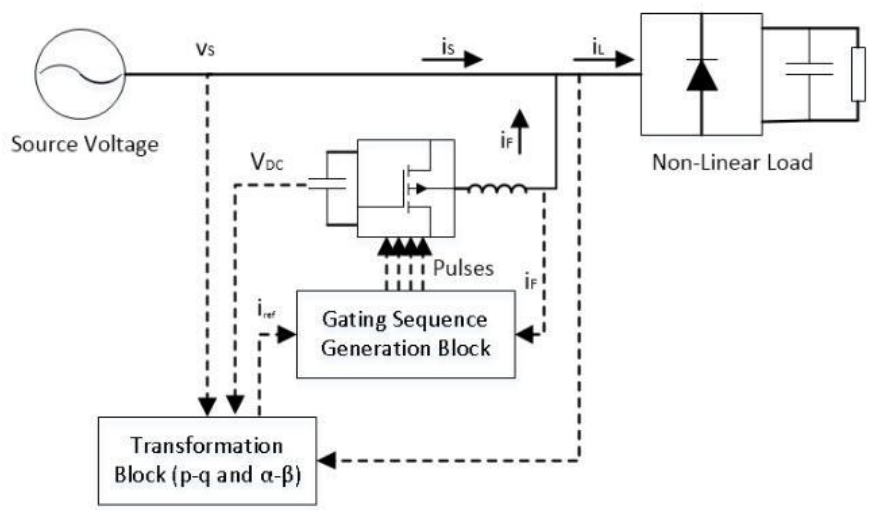

Fig. 2. Shunt Active Power Filter (SAPF) Schematic

\section{THE INSTANTANEOUS POWER THEORY / P-Q THEORY}

The p-q theory deals with the reactive and components of the power and uses the Clarke Transformation, which is also known as the $\alpha-\beta$ transformation [9], [10].

\section{A. Alpha-Beta Transformation}

The Clarke Transformation maps three-phase instantaneous currents $\left(i_{a}, i_{b}\right.$, and $\left.i_{c}\right)$ and voltages $\left(V_{a}, V_{b} V_{c}\right)$ onto the $\alpha-\beta$ frame to obtain $\mathrm{V}_{\alpha}, \mathrm{I}_{\alpha}, \mathrm{V}_{\beta}, \mathrm{I}_{\beta}, \mathrm{V}_{0}$, and $\mathrm{I}_{0}$. The Clarke Transformation of three-phase voltages and currents can be represented in matrix form as [11]:

$$
\begin{aligned}
& {\left[\begin{array}{l}
V_{o} \\
V_{\alpha} \\
V_{\beta}
\end{array}\right]=\sqrt{2 / 3}\left[\begin{array}{ccc}
1 / \sqrt{2} & 1 / \sqrt{2} & 1 / \sqrt{2} \\
1 & -1 / 2 & -1 / 2 \\
0 & \sqrt{3 / 2} & \sqrt{3 / 2}
\end{array}\right]\left[\begin{array}{l}
V_{a} \\
V_{b} \\
V_{c}
\end{array}\right]} \\
& {\left[\begin{array}{l}
i_{0} \\
i_{\alpha} \\
i_{\beta}
\end{array}\right]=\sqrt{2 / 3}\left[\begin{array}{ccc}
1 / \sqrt{2} & 1 / \sqrt{2} & 1 / \sqrt{2} \\
1 & -1 / 2 & -1 / 2 \\
0 & \sqrt{3 / 2} & \sqrt{3 / 2}
\end{array}\right]\left[\begin{array}{l}
i_{a} \\
i_{b} \\
i_{c}
\end{array}\right]}
\end{aligned}
$$

One main advantage of using the $\alpha-\beta$ transformation that it separates the 0 -sequence component of load current that will simplify the equations for further calculations. For this case, the real and imaginary power components are given by:

$$
\left[\begin{array}{l}
p \\
q
\end{array}\right]=\left[\begin{array}{cc}
V_{\alpha} & V_{\beta} \\
V_{\beta} & V_{\alpha}
\end{array}\right]\left[\begin{array}{l}
i_{\alpha} \\
i_{\beta}
\end{array}\right]
$$

Ideally, the only component of power demand by load should only be the average value of the instantaneous real power $\mathrm{P}_{\text {avg }}$ from the source and all other power components, harmonic and reactive, should be supplied or compensated by the SAPF. To find compensation current, in $\alpha-\beta$ coordinate, we will proceed as [12], [13]:

$$
p_{\text {reg }}=k_{p}\left(V_{r e f}-V_{d c}\right)
$$

The value of $p_{x}$ that defines the power to be compensated is given by [14]

$$
\begin{gathered}
p_{x}=\left(p-p_{\text {avg }}\right)-p_{\text {reg }} \\
q_{x}=q
\end{gathered}
$$

Load currents can be used to retrieve the compensation current in the 0-coordinate by the following expression:

$$
\begin{gathered}
{\left[\begin{array}{c}
i_{\text {ref }_{\alpha}} \\
i_{\text {ref }_{\beta}}
\end{array}\right]=\frac{1}{V_{\alpha}^{2}+V_{\beta}^{2}}\left[\begin{array}{cc}
V_{\alpha} & V_{\beta} \\
-V_{\beta} & V_{\alpha}
\end{array}\right]\left[\begin{array}{l}
p_{x} \\
q_{x}
\end{array}\right]} \\
i_{r f_{0}}=i_{L_{0}}=\frac{1}{\sqrt{3}}\left(i_{a}+i_{b}+i_{c}\right)
\end{gathered}
$$

The reference currents in the three-phase system $\left(\mathrm{I}_{\text {refa }}, \mathrm{I}_{\text {refb }}, \mathrm{I}_{\text {refc }}\right)$ are recalculated by using the inverse Clarke Transformation to the currents in the $\alpha-\beta$ coordinate system. [15]

$$
\left[\begin{array}{l}
i_{r e f_{a}} \\
i_{r e f_{b}} \\
i_{r e f_{c}}
\end{array}\right]=\sqrt{2 / 3}\left[\begin{array}{ccc}
1 / \sqrt{2} & 1 & 0 \\
1 / \sqrt{2} & -1 / 2 & \sqrt{3 / 2} \\
1 / \sqrt{2} & -1 / 2 & -\sqrt{3 / 2}
\end{array}\right]\left[\begin{array}{l}
i_{r e f_{0}} \\
i_{r f_{\alpha}} \\
i_{r e f_{\beta}}
\end{array}\right]
$$

\section{B. Reference Current Generation Block}

The estimation of reference current is the most crucial step in which load currents and source voltages are measured and Clark Transformation is used. These quantities are mapped on a two- 
axis frame of reference. Also, real and reactive powers are calculated by these components by the formulas discussed earlier. After that, the harmonic and reactive components of the power are separated by using a low-pass filter. Only those components of power are considered by the SAPF that are responsible for the harmonics and power loss at the inverter, not the actual power demand of the connected non-linear load. [5]

\section{Hysteresis Band Current Controller}

Hysteresis current control is an efficient method to control the output of an inverter. It helps to keep the output current close to the reference current waveform by comparing continuously and eliminating the error. At the point when values of actual current $\mathrm{I}_{\text {comp }}$ exceeds the reference current $\mathrm{I}_{\text {ref }}$, the comparators control flags in such a way to diminish the source current and keep it within the defined band. The same thing happens vice versa when the current is falling below the lower defined limit of the hysteresis band. The error is treated by the HBCC to generate the gating sequence for the switches of VSI. The SAPF will generate output such that the current will become sinusoidal and the harmonic current components are compensated [16], [17].

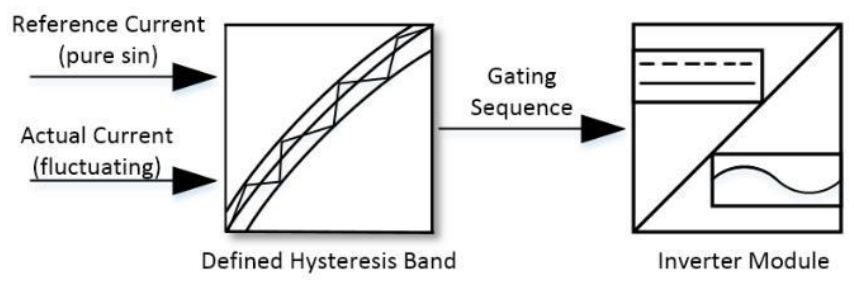

Fig. 3. Block Diagram Hysteresis Current Control

Hysteresis band current control technique is given preference because its implementation is easy and not expensive, also its dynamic response is excellent. However, in this control technique, it is absurd to expect to fix the commutation frequency. In our case, this inconvenience is minor. The current controllers dependent on this strategy are presently utilized as a standard in most current control systems [18].

\section{P-Loss Calculation Block}

The difference between the voltage across DC-Link Capacitor $\mathrm{V}_{\text {cap }}$ and $\mathrm{V}_{\text {ref }}$ is fed to a PI-controller to keep $\mathrm{V}_{\text {cap }}$ constant. As the DC-link capacitor is supposed to provide the real power difference between load and the source during transients while acting as an energy storage component. $\mathrm{P}_{\text {loss }}$ is the real power calculated to cater to switching-losses at the inverter [5].

\section{SYSTEM PARAMETERS}

In this section, we will be discussing the circuit parameters and components used e.g. Non-linear load, DC-link Capacitor, MOSFET based Inverter, etc. [19]

\section{A. Non-Linear Load}

To have non-sinusoidal current components (harmonics) in the power line, we utilized a bridge rectifier with an RL branch in parallel having a resistance of $1 \mathrm{k}$ Ohm capable of holding $100 \mathrm{~W}$ of power and inductor of $100 \mathrm{mH}$ inductance.

\section{B. Circuit Parameters}

The values of the components used in the power and control circuits are given in Table I:

TABLE I

System and component parameters

\begin{tabular}{|l|l|}
\hline Phase to Phase RMS Voltage & $400 \mathrm{~V}$ \\
\hline Fundamental Frequency & $50 \mathrm{~Hz}$ \\
\hline Resistance of Coupling Inductor & $50 \mathrm{~m}$ \\
\hline Inductance of Coupling Inductor & $5 \mathrm{mH}$ \\
\hline DC-Link Capacitor (each) & $470 \mu \mathrm{F}$ \\
\hline Resistance of Non-Linear Load & $1 \mathrm{kOhm}$ \\
\hline Inductance of Non-Linear Load & $100 \mathrm{mH}$ \\
\hline
\end{tabular}

\section{SIMULATION RESULTS OF THREE-PHASE SAPF}

In this model, the most important block is the "Reference Current Generation Block" The reference current generated by this block is compared against the compensating current in the "Hysteresis Band Current Controller" block to generate the gating sequence that is being provided to " 3 -Phase Inverter". The measured capacitor voltage from this block is then fed to the "P-loss Calculation" block to keep it constant using a PIcontroller using a reference voltage.

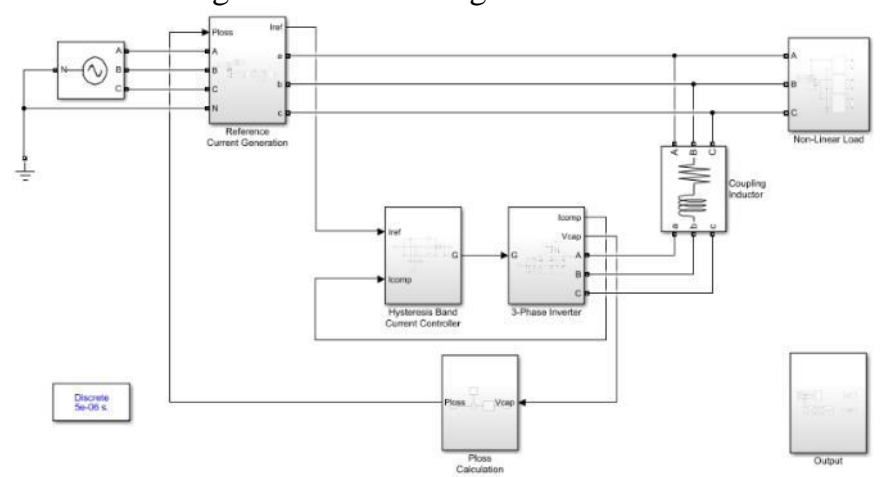

Fig. 4. Simulink Model of Three-Phase SAPF

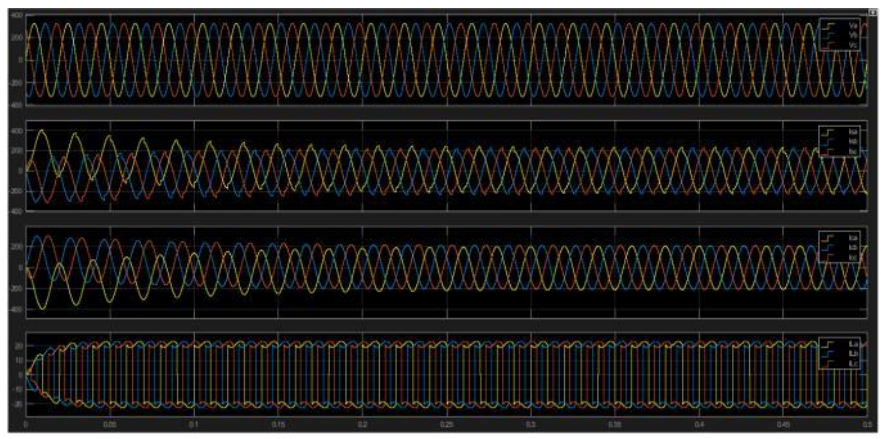

Fig. 5. Source Voltage, Source Current, Compensating Current, Load current respectively

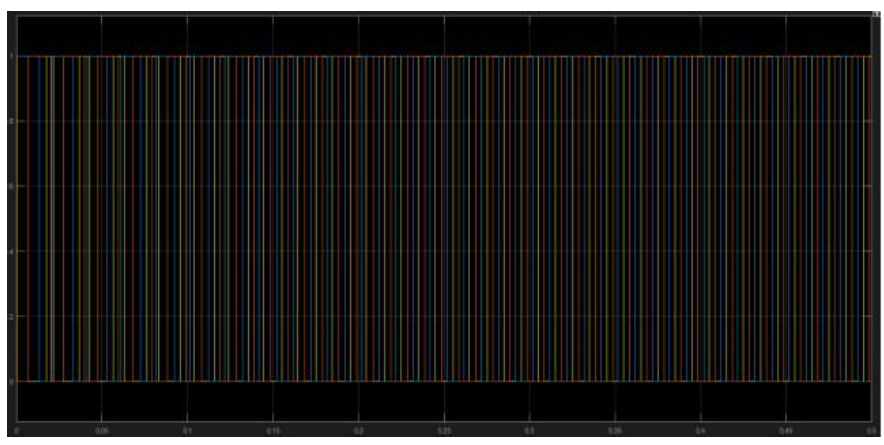


Fig. 6. Gating Sequence

In figure 5, the waveform of the various currents and source voltage involved in the schematic. Figure 6 shows the gating sequence. In Figure 7, the waveform of the DC-Link capacitor voltage and current are shown:

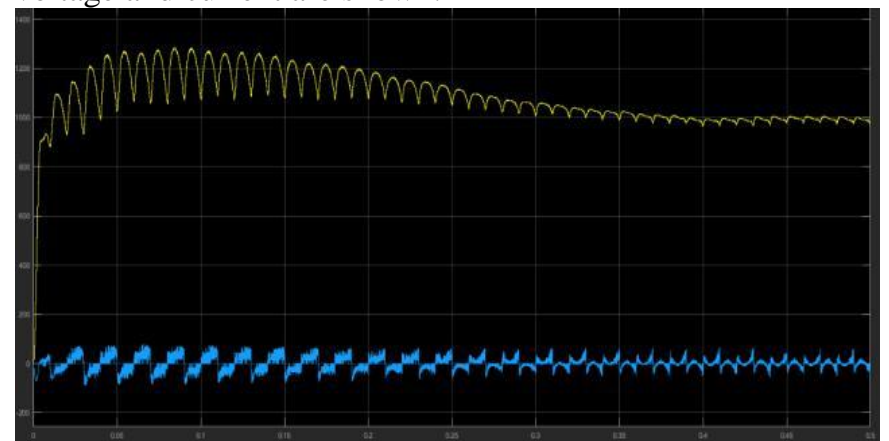

Fig. 7. Voltage and Current Waveform of DC-Link Capacitor

In figure 8, the FFT-Analysis of Load Current. A high value of $47 \%$ has been measured for the non-linear load.
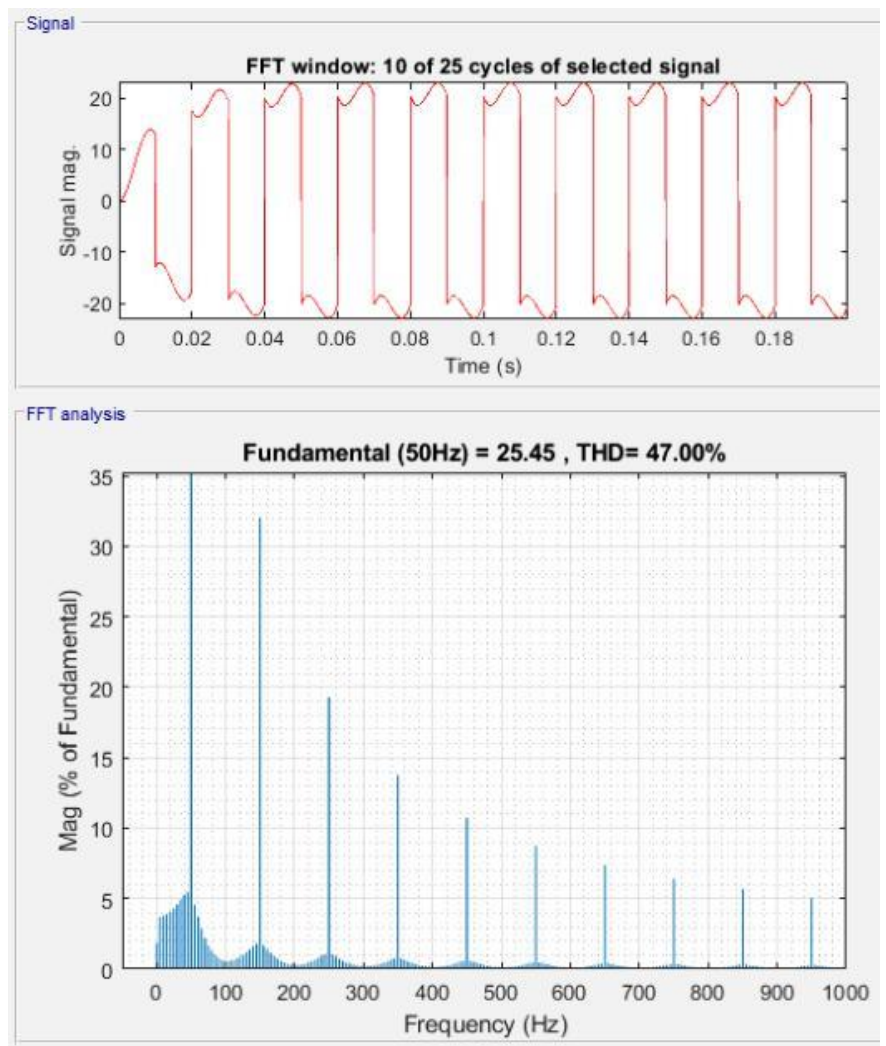

Fig. 8. FFT-Analysis of Load Current

Figure 9 shows the FFT-Analysis of Source Current. In contrast to the load current, the THD value of the source current is reduced to $5.95 \%$ with the utilization of SAPF.

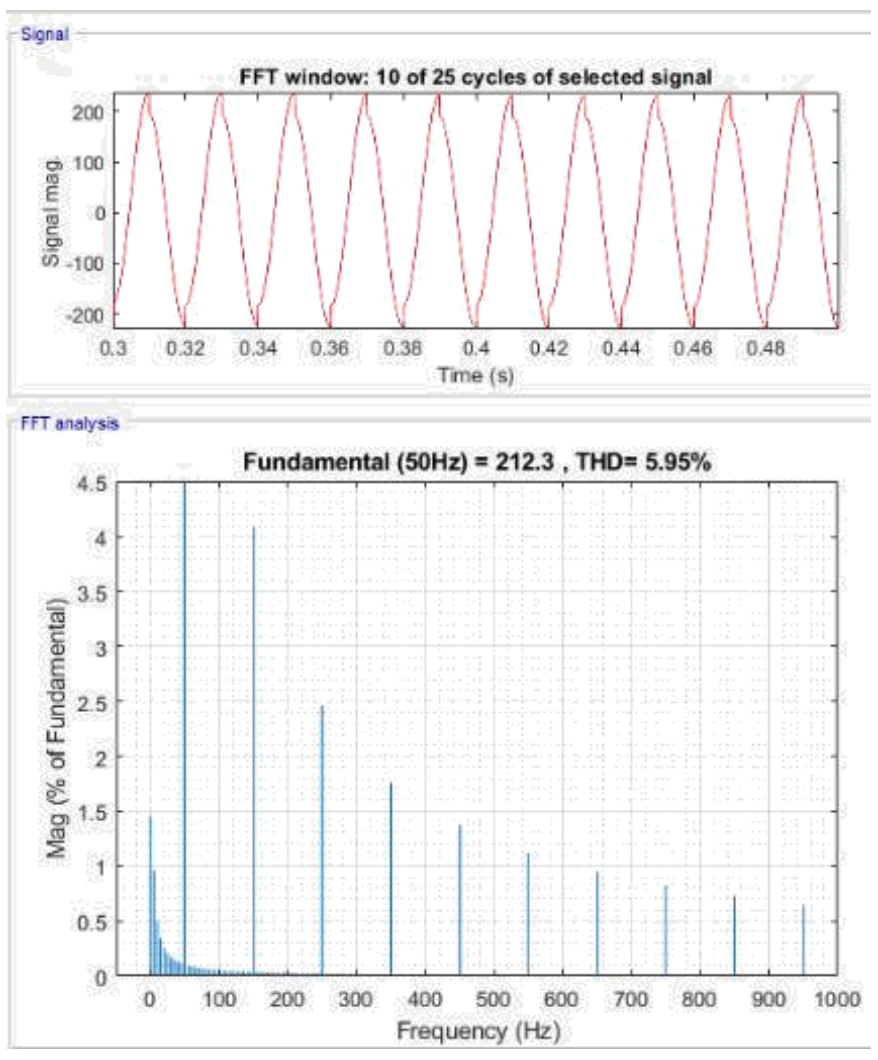

Fig. 9. FFT-Analysis of Source Current

\section{CONCLUSION}

We simulated three-phase SAPF in Simulink and we successfully managed to improve THD\% to a significant level. Also, confining THD\% close to 5\% as per the IEEE-519 standard. By having a comparative FFT-Analysis of load and source currents, we can easily see that the magnitude of the harmonics current components is significantly reduced. Not only the THD, but $\mathrm{PF}$ is also improved as these systems compensate for the reactive power. The simulated system is flexible and its response is dynamic enough to adjust itself as per the change in load, and its power demand. In the end, we can conclude that SAPF is an effective solution for the mitigation of harmonics present in power systems by improving the THD\% and also the PF.

\section{REFERENCES}

[1] S. S. Bhatti, Shan ul Haq, Engr. S. N. M. Gardezi, Engr. M. A. Javaid, "Electric Power Transmission and Distribution Losses Overview and Minimization in Pakistan," International Journal of Scientific \& Engineering Research, vol. 6, April-2015.

[2] A. K. Mohanty, A. K. Barik "Power System Stability Improvement Using FACTS Devices," International 
Journal of Modern Engineering Research (IJMER), vol. 1, pp. 666-672.

[3] M. P. Alexandru Bitoleanu, "The p-q theory and Compensating Current Calculation for Shunt Active Power Filters: Theoretical Aspects and Practical Implementation".

[4] P. N. Chamat, "Control of Three-Phase Shunt Active Power Filter (SAPF) By Instantaneous Reactive Power Theory," International Journal Of Trend In Scientific Research And Development (IJTSRD), vol. 2, Jul-Aug 2018.

[5] S. Vikash Anand, "Performance Investigation of Shunt Active Power Filter Using Hysteresis Current Control Method," International Journal of Engineering Research \& Technology (IJERT), vol. 1, June-2012.

[6] [6] Joao L. Afonso, M. J. Sepulveda' Freitas, and Julio’ S. Martins, "p-q Theory Power Components Calculations," ISIE'2003 - IEEE International Symposium on Industrial Electronics.

[7] P. Tamilselvan, "Multiband and Modified Time Based Hysteresis Current Controller for single-phase Multilevel Inverters," International Journal of Multidisciplinary Educational Research (IJMER), vol. 5, Mar-2015.

[8] J. G. Pinto, Pedro Neves, Ricardo Pregitzer, Lu'1s F. C. Monteiro, Joao L. Afonso, "Single-Phase Shunt Active Filter with Digital Control," in ICREPQ'07International Conference on Renewable Energies and Power Quality, Seville, Spain, 28-30 March.

[9] Y. Fatima, R. Yadav, R. Singh, "Design of Hybrid Multilevel Inverter to Improve the Total Harmonic Distortion," International Journal of Modern Engineering Research (IJMER), vol. 5, July 2015.

[10] P. Dash, P. K. Karjee, K. D. Rao h, "Design of a Fuzzy Controller based Shunt Active Power Filter for 3-Phase Power System for Power Factor Improvement, Harmonic Reduction, Compensating Current," International Journal of Research and Scientific Innovation (IJRSI), vol. 2, April-2015.

[11] H. Akagi, Instantaneous power theory and applications to power conditioning (2nd Edition), John Wiley \& Sons, 2007.

[12] A. Shah, N. Vaghela ah, "Shunt Active Power Filter for Power Quality Improvement in Distribution Systems," International Journal of Engineering Development And Research - Ijedr.

[13] A. Chavada, P. Thakor, B. Nanecha, "Simulation and analysis of shunt active power filter," International Research Journal of Engineering and Technology (IRJET), May-2016.

[14] A. L. Batschauer, "A Voltage Regulator for Power Quality Improvement in Low-Voltage Distribution Grids.," IEEE Transactions on Power Electronics, vol. 33, no. 3, March 2018.

[15] J. Afonso, C. Couto, J. Martins, "Active Filters with Control Based on the p-q Theory," IEEE Industrial
Electronics Society Newsletter, vol. 47, pp. 5-10, Sept2000.

[16] V. K. Saxena, A. Ranjan, "MATLAB Simulink for single-phase PWM inverter in an uninterrupted power supply," International Journal of Multidisciplinary Educational Research (IJMER), vol. 4, June-2014.

[17] P. V. R. Kumar, M. S. Kalavathi, "Fuzzy Based Hysteresis Current Controlled Shunt Active Power Filter for Power Conditioning," International Journal of Modern Engineering Research (IJMER), vol. 3, pp. 77485, Jan-Feb 2013.

[18] S. Mikkili, A. K. Panda, "Instantaneous Active and Reactive Power and Current Strategies for Current Harmonics Cancellation in 3-ph 4-Wire SHAF with Both PI and Fuzzy Controllers," Energy and Power Engineering http://www.SciRP.org/journal/epe, vol. 3, pp. 285-298, 2011.

[19] Y. A. Elshrief, G. A. Atlam, B. A. Abozalalm, "Adaptive - Fuzzy Logic Power Filter for Nonlinear Systems," IOSR Journal of Electrical and Electronics Engineering (IOSR-JEEE), vol. 11, Mar-Apr 2016.

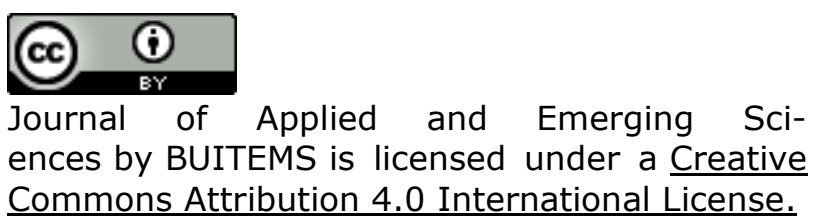

